\section{Letter to the Editor}

Check for updates

\section{OPEN ACCESS}

Received: Feb 28, 2020

Accepted: Mar 16, 2020

Correspondence to

Yong-Seog Oh, MD, PhD

Division of Cardiology, Department of Internal

Medicine, Seoul St. Mary's Hospital, College

of Medicine, The Catholic University of Korea,

222, Banpo-daero, Seocho-gu, Seoul 06591,

Korea.

E-mail: oys@catholic.ac.kr

Copyright (c) 2020. The Korean Society of Cardiology

This is an Open Access article distributed under the terms of the Creative Commons Attribution Non-Commercial License (https:// creativecommons.org/licenses/by-nc/4.0) which permits unrestricted noncommercial use, distribution, and reproduction in any medium, provided the original work is properly cited.

ORCID iDs

Sunhwa Kim (D)

https://orcid.org/0000-0003-3109-9210 Yoo Ri Kim (D)

https://orcid.org/0000-0001-7351-1299

Young Choi (D)

https://orcid.org/0000-0003-3900-1943

Sung-Hwan Kim (D)

https://orcid.org/0000-0001-6805-0416

Yong-Seog Oh (D)

https://orcid.org/0000-0003-3567-6505

Conflict of Interest

The authors have no financial conflicts of interest.

Author Contributions

Project administration: Oh YS; Supervision: Kim SH, Choi Y; Writing - original draft: Kim SH; Writing - review \& editing: Kim YR.

\title{
Author's reply to The Long Journey of Cardiac Lymphoma Follow-up
}

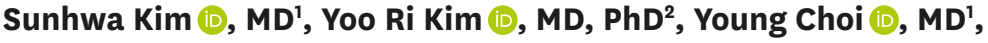 \\ Sung-Hwan Kim $\mathbb{1}, \mathrm{MD}, \mathrm{PhD}^{\prime}$, and Yong-Seog Oh $\mathbb{1}, \mathrm{MD}, \mathrm{PhD}^{1}$
}

'Division of Cardiology, Department of Internal Medicine, Seoul St. Mary's Hospital, College of Medicine, The Catholic University of Korea, Seoul, Korea

${ }^{2}$ Division of Cardiology, Department of Internal Medicine, Dongguk University Ilsan Hospital, Goyang, Korea

- See the letter "The Long Journey of Cardiac Lymphoma Follow-up” in volume 50 on page 533.

Thank you for the so important comment.

Unfortunately, the end-of-therapy fluorodeoxyglucose (FDG) positron emission tomography (PET)/computed tomography (CT) image was not obtained after proper protocol to inhibit the physiologic uptake of the myocardium, as the patient was mistakenly considered as routine oncology case. From the fact that the interim FDG PET/CT was negative and that the mediastinal FDG uptake was resolved, we considered the remnant uptake of the heart on end-of-therapy FDG PET/CT to be physiologic. We regret that we did not prepare the patient with the cardiac protocol of low carbohydrate diet and longer fasting time. Subsequent follow-up studies over a year and half have demonstrated no evidence of tumor recurrence.

But the patient has been completely in normal life, and transthoracic echocardiogram, and electrocardiogram (ECG), 24 hours ECG monitoring showed the same as for 3-4 year. If we have another chance to check up FDG PET/CT, then we will do cardiac preparation. 